\title{
THE EFFECTS OF COLLECTIVISM AND SOCIAL NETWORK SELF-CONGRUITY ON ENGAGEMENT
}

\author{
Sara Santos ${ }^{1}$ and Pedro Espírito Santo ${ }^{2}$ \\ ${ }^{1}$ Escola Superior de Educação de Coimbra, R. Dom João III, 3030-329 Coimbra, Portugal \\ ${ }^{2}$ Instituto Politécnico de Coimbra, ESTGOH, Rua Gen. Santos Costa, 3400-124 Oliveira do Hospital, Portugal
}

\begin{abstract}
In recent years, social media and special social networks are being part of people's everyday lives and consumers use a variety of social media channels daily. For firms, it has become a key tool in the promotion of brands, products and services. Furthermore, people have different characteristics of individualism, collectivism and congruity with social networks. However, empirical research on consumer-brand engagement on social networks is still scarce.

The aim of this research is to understand the relation among collectivism, self-congruity with social network and social networks engagement.

Using an online questionnaire conducted across 484 participants in Portugal, the results show that collectivism has a positive influence on social network engagement (consumption and contribution).

Our finds also reveal that self-congruence of individuals has influence on their engagement with social networks.

In practical implications, marketers should see the values and lifestyle of their users to improve their social networks pages.
\end{abstract}

\section{KEYWORDS}

Collectivism, Individualism, Self-Congruity, Social Networks, Engagement

\section{INTRODUCTION}

In recent years the exponential growth of social media and special social networks sites leads to increase of interactions and continuous connection between users and brands, between users and even between brands and brands. It is important to distinguish between social media and social networks sites. Kaplan \& Haenlein (2010) consider that social media facilitates interaction, collaboration and content sharing and there are six types of social media plataforms: blogs (Wordpress, Tumblr or Twitter - microblogging), collaborative sites (e.g. Wikipedia), content creation communities (e.g, YouTube), virtual worlds (World of Warcraft), virtual social worlds (e.g, Second Life) and social networking sites. Social network sites are "web-based services that allow individuals to construct a public or semi-public profile within a bounded system, articulate a list of other users with whom they share connection, and view and traverse their list of connections made by others within the system" (Boyd \& Ellison, 2007, p. 211).

In this study we analyze the relation among collectivism, self-congruity with social network and social networks engagement (consumption and contribution).

\section{LITERATURE REVIEW}

\subsection{Social Networks Engagement}

In the last decade consumer engagement, namely consumer-brand-engagement (CBE) has been the target of several studies (Hollebeek, Glynn, \& Brodie, 2014). However, there is no consensus regarding its definition (Dessart, Veloutsou, \& Morgan-Thomas, 2015). 
Social media engagement is a specific context of consumer engagement (Brodie, Ilic, Juric, \& Hollebeek, 2013) and it could begin with "liking" a Facebook page (Beukeboom, Kerkhof, \& de Vries, 2015). In order to analyze this engagement in social media, Muntinga, Moorman, \& Smit (2011) proposed a Consumer Online Brand-Related Activity (COBRA) model which distinguishes consumer engagement in three types of behavior (from lower to higher engagement): consumption (when consumers view images and videos, read information, comments and reviews), contribution (when users like or comment photographs and videos and engage in conversations about the brand); creation - users produce and publish content related to the brand (Mutinga et al., 2011). These users proactively create brand content on their personal networks (Men \& Tsai, 2014).

\subsection{Individualism / Collectivism}

Culture, defined as the patterns shared by individuals in a society, represents the dominant values of a set of people and are socially accepted (Frank, Enkawa, \& Schvaneveldt, 2015). Culture represents the values of most people and influences the behavior of individuals in their personal behavior.

In this context, it is accepted in the literature that individualism as opposed to the collectivism of individuals depends on the culture of each individual (Hofstede, 1984) since as individuals internalize the norms, rules, and values in a society they share the perception of their social environment that modifies the way individuals behave, interact, and build relationships (Kim, Sohn, \& Choi, 2011).

Based on the analysis by Kim et al. (2011) the role of culture in communication has been studied by comparing two distinct cultures - individualism and collectivism. Goncalo and Staw (2006) describe that the cultural values of individualism and collectivism differ in their relation to the group. These authors report the study of Markus and Kitayama (1994) to explain that in individualistic cultures, people are seen as independent and have a unique pattern of characteristics that distinguish them from others while in collectivist cultures people are linked to their social group (Kim et al., 2011).

Thus, the two types of individuals (individualists and collectivists) have distinct communication styles. Kim et al. (2011) recognizes that individuals with a higher level of collectivism tend to communicate and interact more with groups, so this study will test the following research hypothesis:

H1a: the level of collectivism of individuals has a positive influence on the consumption of content in social networks.

$\mathrm{H} 1 \mathrm{~b}$ : the level of collectivism of individuals has a positive influence on the contributions of individuals in social networks.

\subsection{Social Network Self-Congruity}

In brand relationships with individuals, brand proximity in terms of beliefs, values and personality is defined as the self-congruence of the brand with the individual ( $\mathrm{Su}$ et al., 2015). In this sense, congruence with a brand is a mental representation (Beerli, Meneses, \& Gil, 2007) and refers to the relevance, adequacy or compatibility between a brand and the image each individual has of himself.

In the field of brands management, congruence has been analyzed and, in this context, Sirgy, Lee, Johar, and Tidwell (2008) describe that the results in the literature demonstrate the significant influence of this congruence with the brand, the brand image (Sirgy, 1982, 1986) social interactions and emotional attachment to the brand (Beerli et al., 2007).

According to the theory, individuals tend to prefer brands that are congruent with their identities (Hollenbeck \& Kaikati, 2012). As social networks improve collaboration between individuals, the relationship between the level of collectivism and the self-congruence of the individual with social networks is real. This relationship arises through the facilitation, acquisition and diffusion of knowledge (Bodin \& Crona, 2009). In this sense, this study aims to test the following hypothesis of investigation:

$\mathrm{H} 2$ : the level of collectivism has positive effects on self-congruence (individual-social networks).

Therefore, this study investigated how users use social networks as a consequence of their self-congruence that, based on the study of Koo, Cho, and Kim (2014), it is possible to affirm that the degree to which the images of a brand correspond to the self-image of the individuals exerts a significant influence on the behavior of the consumer in several contexts, namely when forming online attitudes. Thus, this study aims to test the following hypothesis of investigation: 
H3: Self-congruence of individuals influences their engagement with social networks.

H3a: Self-congruence of individuals influences their consumption of social networks

H3a: Self-congruence of individuals influences their contribution with social networks

Schivinski et al. (2016) based on the COBRA model (Muntinga et al., 2011), consider that there is a hierarchical relationship between the three dimensions of engagement: consumption, contribution and creation. This study analyzes whether the same hierarchical relationship (consumption-contribution) happens. Thus, the last hypothesis is:

H4: Consumption of content in social networks has influence on contribution.

This formulation of hypothesis resulted in the conceptual model shown in figure 1.

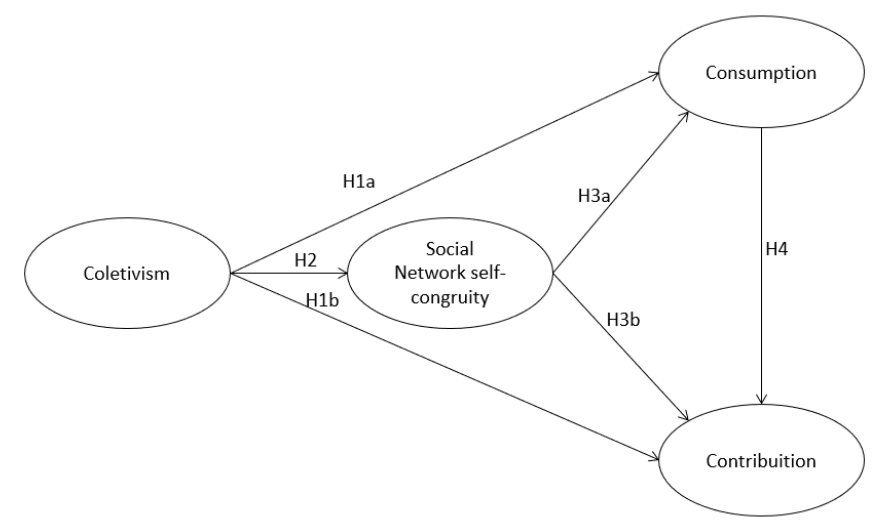

Figure 1. Conceptual Model

\section{METHODOLOGY}

The present study of a conclusive-causal nature had simple transversal characteristics whose unit of analysis were the individuals that use social networks in general. The request for the questionnaire response was sent by sharing the questionnaire link through different social networks guaranteeing the anonymity of the individual's response. Considering the concepts under study, the concepts were operationalized through 5-point Likert scales, already tested in the literature and whose original studies of which were adapted are described in table 1.

Table 1. Constructs, Items and References

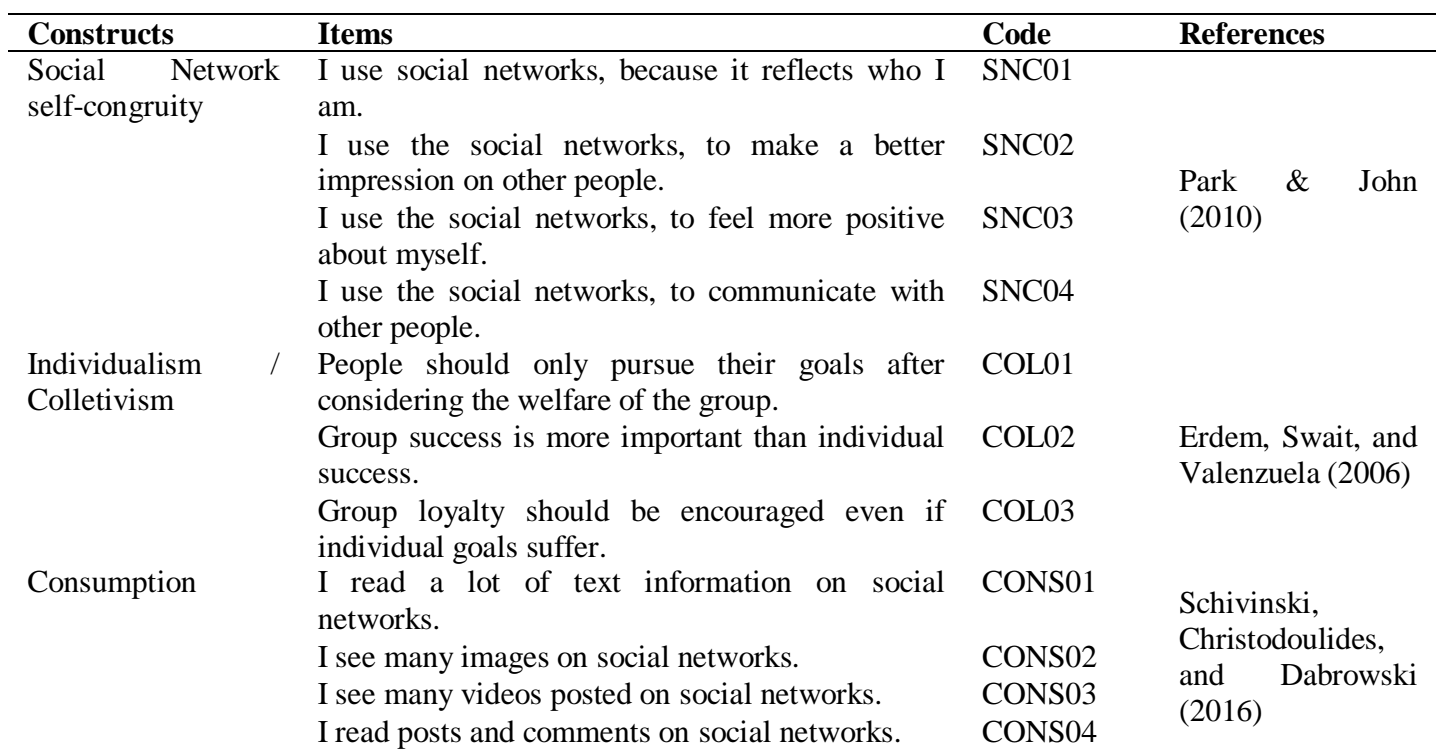


Contribution

I click the like button in many publications.

I often comment on publications, videos and images.

I often share the publications with friends.

I comment on publications, videos and images of unknown people.
CONT01

CONT02

CONT03

CONT04
(2016)

From the data obtained, 484 responses were obtained from respondents whose characteristics are shown in table 2 .

Table 2. Demographic Characteristics of Respondents

\begin{tabular}{llll}
\hline Variable & Category & Frequency & Valid \% \\
\hline Gender & Male & 152 & 31,4 \\
& Female & 332 & 68,6 \\
\hline Age & Until 20 years & 226 & 47,5 \\
& 20 to 29 years & 178 & 37,4 \\
& 30 to 39 years & 39 & 8,2 \\
& 40 to 49 years & 27 & 5,7 \\
& 50 to 59 years & 5 & 1,1 \\
& 60 to 69 years & 1 & 0,2 \\
\cline { 2 - 4 } & Missing values & 8 & \\
\hline
\end{tabular}

Following the previous analysis to the data, where the existence of outliers and the non-existence of multicollinearity $(\mathrm{VIF}<5)$ the model was estimated through the method of analysis of structural equations by partial least squares (PLS-SEM) (Hair, Hult, Ringle, \& Sarstedt, 2016).

The first step is to analyze the measurement model whose objective is to evaluate the capacity of the items under study and measure their concepts in terms of reliability and validity. The evaluation to the measurement model provides confirmatory information about the reliability, factorial validity, convergent validity and discriminant validity of the constructs. This step was executed through the "PLS algorithm" function in the software SMART PLS version 3.2.7. The results obtained for the measurement model are shown in table 3 .

Table 3. Results of the Measurement Model

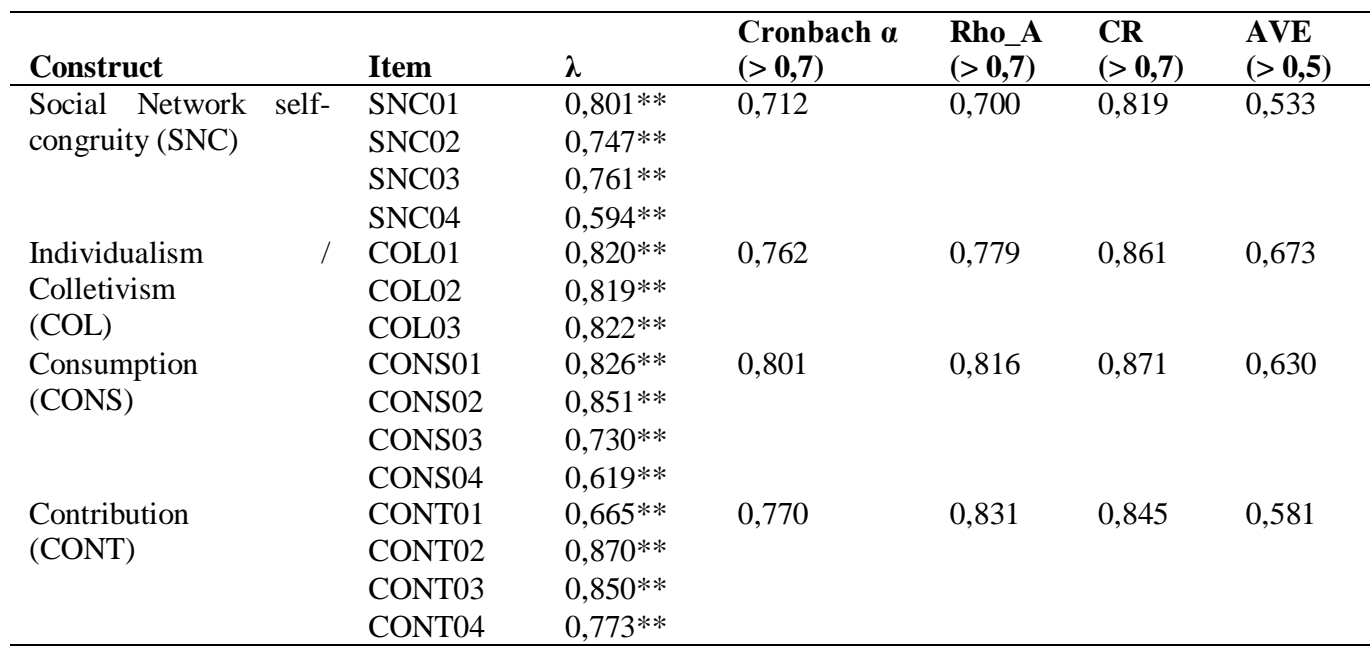

$\lambda$ - Standardized Coefficients (Standardized Loadings); AVE - Average Extracted Variance; CR - Composite reliability; $* * \mathrm{p}<0,01$

The analysis of the standardized coefficients $(\lambda)$ verifies that these are greater than 0.5 and their significance is considered for $\mathrm{p}<0,01$. It is considered the existence of factorial validity, convergent validity and composite reliability. The Cronbach $\alpha$ values are greater than $0.7(\alpha>0,7)$. 
In this study the analysis of the discriminant validity was evaluated through the following criteria: criterion of Fornell and Larcker (1981), cross-load analysis criterion and Heterotrait-Monotrait correlation coefficient analysis criterion (HTMT) (Henseler, Ringle, \& Sarstedt, 2015). The results obtained for the analysis of the discriminant validity by the criterion of Fornell and Larcker (1981) are present in table 4.

Table 4. Discriminating Validity - criterion of Fornell and Larcker (1981)

\begin{tabular}{lllll}
\hline & COL & SNC & CONS & CONT \\
\hline Individualism / Colletivism(COL) & 0,820 & & & \\
Social Network self-congruity (SNC) & 0,283 & 0,730 & & \\
Consumption (CONS) & 0,207 & 0,453 & 0,794 & \\
Contribution (CONT) & 0,132 & 0,416 & 0,417 & 0,762 \\
\hline
\end{tabular}

Table 4 confirms that the square root values of the extracted mean variance, whose values are presented in the main diagonal of the table, are superior to the square of the correlations between the respective constructs, and it is considered that the discriminant validity exists by the criterion of Fornell and Larcker (1981). Cross- loadings present in the items of the model were also analyzed. The results are shown in table 5.

Table 5. Discriminating Validity - Cross-loadings

\begin{tabular}{lcccc}
\hline & COL & SNC & CONS & CONT \\
\hline CONT01 & 0,169 & 0,298 & 0,665 & 0,230 \\
CONT02 & 0,178 & 0,404 & 0,870 & 0,282 \\
CONT03 & 0,175 & 0,385 & 0,850 & 0,298 \\
CONT04 & 0,141 & 0,343 & 0,773 & 0,471 \\
CONS01 & 0,109 & 0,388 & 0,460 & 0,826 \\
CONS02 & 0,138 & 0,336 & 0,331 & 0,851 \\
CONS03 & 0,075 & 0,274 & 0,251 & 0,730 \\
CONS04 & 0,062 & 0,223 & 0,080 & 0,619 \\
COL01 & 0,820 & 0,287 & 0,188 & 0,110 \\
COL02 & 0,819 & 0,184 & 0,116 & 0,078 \\
COL03 & 0,822 & 0,205 & 0,188 & 0,128 \\
SNC01 & 0,193 & 0,801 & 0,291 & 0,410 \\
SNC02 & 0,228 & 0,747 & 0,142 & 0,297 \\
SNC03 & 0,255 & 0,761 & 0,154 & 0,264 \\
SNC04 & 0,163 & 0,594 & 0,577 & 0,220 \\
\hline
\end{tabular}

The results of Table 5 show discriminant validity since the coefficients (loadings) are higher than cross loadings for each item. For the discriminant analysis were also analyzed the correlation ratio of Heterotrait-Monotrait. The values that were obtained are present in table 6 (Henseler et al., 2015).

Table 6. Discriminating Validity - ratio of Heterotrait-Monotrait

\begin{tabular}{lllll}
\hline & COL & SNC & CONS & CONT \\
\hline Individualism / Colletivism(COL) & & & & \\
Social Network self-congruity (SNC) & 0,376 & & & \\
Consumption (CONS) & 0,258 & 0,523 & & \\
Contribution (CONT) & 0,157 & 0,543 & 0,452 & \\
\hline
\end{tabular}


According to the Heterotrait-Monotrait criterion, there is a discriminant validity, since the values presented (table 6) are lower than 0.9 as indicated in the literature (Henseler et al., 2015).

Thus, the three criteria analyzed for the discriminant validity items confirm what is recommended in the literature, which leads to consider that the items have distinction between them. Therefore, the data obtained suggest that there is a discriminant validity so that we can proceed with the analysis to the structural model.

The second step is the analysis to the structural model through the evaluation of the structural path coefficients and analysis to their significance.

The second step of the analysis is the test to the structural model. For this purpose, we used the bootstrap resampling technique with 5000 sub-samples in order to be able to have stability in the obtained results. The accomplishment of this analysis allowed to obtain the results that will be used to test the hypotheses under study.

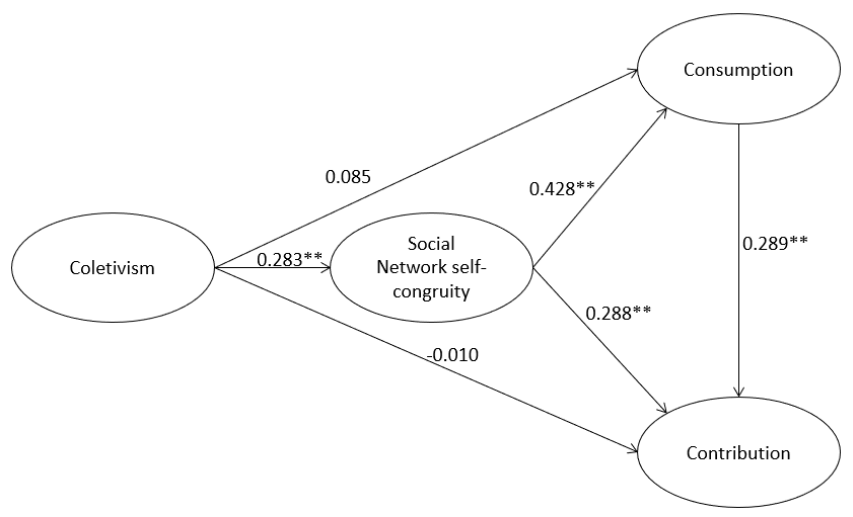

Figure 2. Structural Model

These results will be analyzed considering the values standardized $\beta$ (table 7 ) and $t$ Student values. This analysis will serve to validate the statistical significance of the parameters under analysis. Therefore, the results are summarized on the table 7 .

Table 7. Hypothesis Testing - Direct, Indirect and Total Effects

\begin{tabular}{|c|c|c|c|c|c|c|c|c|}
\hline & & \multicolumn{2}{|c|}{ Direct Effects } & \multicolumn{2}{|c|}{ Indirect Effects } & \multicolumn{2}{|c|}{ Total Effects } & \\
\hline & $\begin{array}{l}\text { Relationship to } \\
\text { be tested }\end{array}$ & $\beta$ & t values & $\beta$ & t values & $\beta$ & t values & \\
\hline $\mathrm{H} 1 \mathrm{a}$ & $\mathrm{COL} \rightarrow \mathrm{CONS}$ & 0.085 & 1.880 & 0.121 & 4.832 & 0.207 & 3.986 & Supported* \\
\hline $\mathrm{H} 1 \mathrm{~b}$ & $\mathrm{COL} \rightarrow \mathrm{CONT}$ & -0.010 & 0.213 & 0.141 & 4.969 & 0.132 & 2.670 & Supported* \\
\hline $\mathrm{H} 2$ & $\mathrm{COL} \rightarrow \mathrm{SNC}$ & 0.283 & 5.741 & -------- & -------- & 0.283 & 5.741 & Supported \\
\hline $\mathrm{H} 3 \mathrm{a}$ & $\mathrm{SNC} \rightarrow \mathrm{CONS}$ & 0.428 & 8.604 & -------- & -------- & 0.428 & 8.604 & Supported \\
\hline $\mathrm{H} 3 \mathrm{~b}$ & $\mathrm{SNC} \rightarrow \mathrm{CONT}$ & 0.288 & 5.235 & 0.124 & 4.189 & 0.412 & 9.531 & Supported \\
\hline $\mathrm{H} 4$ & $\mathrm{CONS} \rightarrow \mathrm{CONT}$ & 0.289 & 5.593 & -------- & --------- & 0.289 & 5.593 & Supported \\
\hline
\end{tabular}

* Hypothesis corroborated by indirect effects

Source: self elaboration

\section{DISCUSSION}

The results evidenced the explanation of the engagement in social networks by the variables included in the model. This analysis is done through two dimensions: the consumption of individuals $\left(\mathrm{R}^{2}\right.$ cons $\left.=0,211\right)$ and the contribution $\left(\mathrm{R}^{2}\right.$ CONT $\left.=0,239\right)$ of individuals in social networks.

In the analysis of the hypothesis test carried out through the structural model, the individual or collectivistic characteristics of the individuals do not have significant direct effects on the engagement in social networks. This analysis is done by the values presented for the hypothesis H1a $\left(\beta_{\mathrm{COL} \rightarrow \mathrm{CONS}}=-0.010\right.$; $t=0,711 ; p>0,05)$ and for the hypothesis $\mathrm{H} 1 \mathrm{~b}\left(\beta_{\mathrm{COL} \rightarrow \mathrm{CONT}}=0.085 ; t=1.880 ; p>0,05\right)$ from which it is verified that the direct effects of the collectivism of the individuals do not contribute to the explanation of the consumption nor the contribution of the individuals in the social networks. This analysis can make sense, 
since the respondents are individuals belonging to countries of the European Union very associated with low levels of collectivism and may not have corroborated the hypotheses H1a and H1b.

However, the engagement in the social networks of individuals has as a determining variable the congruence with the social network. This analysis is based on the results of the hypothesis H3a $\left(\beta_{\mathrm{SNC} \rightarrow \mathrm{CONS}}=0.428 ; t=8.604 ; p<0,001\right)$ and the hypothesis $\mathrm{H} 3 \mathrm{~b}\left(\beta_{\mathrm{SNC} \rightarrow \mathrm{CONT}}=0.288 ; t=5.235 ; p<0.001\right)$. In addition to this analysis, the congruence with the social network with the individuals has a mediating capacity in the corroboration of the hypothesis $\mathrm{H} 1 \mathrm{a}\left(\beta_{\mathrm{COL} \rightarrow \mathrm{SNC} \rightarrow \mathrm{CONS}}=0.121 ; t=4.832 ; p<0,001\right)$ and the hypothesis $\mathrm{H} 1 \mathrm{~b}\left(\beta_{\mathrm{COL} \rightarrow \mathrm{SNC} \rightarrow \mathrm{CONT}}=0.141 ; t=4.969 ; p<0,001\right)$ contributing for its indirect effects to be important so that the collectivism of the individuals is an important variable in the explanation of the engagement in the social networks thus supporting the hypothesis $\mathrm{H} 1 \mathrm{a}$ and $\mathrm{H} 1 \mathrm{~b}$, justifying the assertion of Kim et al. (2011) in the sense that individuals with a higher level of collectivism are more connected to the group, that through this study, it is verified that individuals connect to social networks if this social network has values appropriate to individuals.

\section{CONCLUSION}

Due to the centrality of social networks today, the empirical study presented here contributed to the advance of theoretical knowledge and has practical implications for management.

In the theoretical scope, this study presents as main contribution the importance of the self-congruence of the individuals with the social network so that it improves its engagement. Therefore, this work demonstrates that the engagement of individuals is directly due to the congruence of the values of individuals and the values of social networks, but also the collectivist culture promotes higher levels of engagement in social networks.

As practical contributions, this work has implications for companies, demonstrating that the management of social networks must consider the individual and his own values, without forgetting the culture in which they are inserted, by the importance that the collectivist culture must determine the consumption of content and the contribution of individuals in social networks.

In summary, this work has valid conclusions, however some limitations of investigation have arisen. From the limitations, the fact that the data were collected from a sample of young individuals up to the age of 30, in most cases. This evidence may have left out some conclusions that could be important to draw from the model under analysis. Another limitation is the analysis of a sample of individuals, not comparing different groups of people.

Thus, it is suggested that for future studies the data collection should be performed to a more balanced sample in the respondents' ages and that groups of individuals be compared in order to obtain more precise explanations about the engagement of individuals in social networks.

\section{REFERENCES}

Baldus, B. J. et al, 2015. Online brand community engagement: Scale development and validation. Journal of Business Research, Vol.68, No.5, pp. 978-985.

Beerli, A. et al, 2007. Self-congruity and destination choice. Annals of Tourism Research, Vol. 34, No.3, pp. 571-587.

Beukeboom, C. et al, 2015. Does a Virtual Like Cause Actual Liking? How Following a Brand's Facebook Updates Enhances Brand Evaluations and Purchase Intention. Journal of Interactive Marketing, Vol.32, pp. 26-36.

Bodin, Ö. et al, 2009. The role of social networks in natural resource governance: What relational patterns make a difference? Global Environmental Change, Vol. 19, No.3, pp. 366-374.

Boyd, D. et al, 2007. Social Network Sites: Definition, History, and Scholarship. Journal of Computer-Mediated Communication, Vol.13, No.1, pp. 210-230.

Brodie, R. J. et al, 2013. Consumer engagement in a virtual brand community: An exploratory analysis. Journal of Business Research, Vol.66, No.1, pp. 105-114.

Cheung, C. M. K. et al, 2011. Online social networks: Why do students use facebook? Computers in Human Behavior, Vol.27, No.4, pp. 1337-1343. 
Dessart, L. et al, 2015. Consumer engagement in online brand communities: a social media perspective. Journal of Product \& Brand Management, Vol.24, No.1, 28-42.

Erdem, T. et al, 2006. Brands as Signals: A Cross-Country Validation Study, 70, pp. 34-49.

Fornell, C. et al, 1981. Evaluating structural equation models with unobservable variables and measurement error. Journal of Marketing Research, Vol.18, No.1, pp. 39-50.

Frank, B. et al, 2015. The role of individualism vs. collectivism in the formation of repurchase intent: A cross-industry comparison of the effects of cultural and personal values. Journal of Economic Psychology, Vol.51, pp. 261-278.

Goncalo, J. A. et al, 2006. Individualism-collectivism and group creativity. Organizational Behavior and Human Decision Processes, Vol.100, No.1, pp. 96-109.

Hair, J. F. et al, 2016. A Primer on Partial Least Squares Structural Equation Modeling (PLS-SEM): SAGE Publications.

Henseler, J. et al, 2015. A new criterion for assessing discriminant validity in variance-based structural equation modeling. Journal of the Academy of Marketing Science, Vol.43, No.1, pp. 115-135.

Hofstede, G. 1984. Culture's Consequences: International Differences in Work-Related Values: SAGE Publications.

Hollenbeck, C. R. et al, 2012. Consumers' use of brands to reflect their actual and ideal selves on Facebook. International Journal of Research in Marketing, Vol.29, No.4, pp. 395-405.

Hollebeek, L. D. et al, 2014. Consumer Brand Engagement in Social Media: Conceptualization, Scale Development and Validation. Journal of Interactive Marketing, Vol.28, No.2, pp. 149-165.

Kaplan, A. M. et al, 2010. Users of the world, unite! The challenges and opportunities of Social Media. Business Horizons, Vol.53, No.1, pp. 59-68.

Kim, Y. et al, 2011. Cultural difference in motivations for using social network sites: A comparative study of American and Korean college students. Computers in Human Behavior, Vol.27, No.1, pp. 365-372.

Koo, W. et al, 2014. Actual and ideal self-congruity affecting consumers' emotional and behavioral responses toward an online store. Computers in Human Behavior, Vol. 36, pp. 147-153.

Men, L. R. et al, 2014. Perceptual, Attitudinal, and Behavioral Outcomes of Organization-Public Engagement on Corporate Social Networking Sites. Journal of Public Relations Research, Vol.26, No.5, pp. 417-435.

Muntinga, D. et al, 2011. Introducing COBRAs. International Journal of Advertising, Vol.30, No.1, pp. 13-46.

Park, J. et al, 2010. Got to Get You into My Life: Do Brand Personalities Rub Off on Consumers? Journal of Consumer Research, Vol.37, pp. 655-669.

Schau, H. J. et al, 2003. We Are What We Post? Self-Presentation in Personal Web Space. Journal of Consumer Research, Vol.30, No.3, pp. 385-404.

Sirgy, J. 1982. Self-Concept in Consumer Behavior: A Critical Review. Journal of Consumer Research, Vol. 9, No.3, pp. 287-300.

Sirgy, J. 1986. Self-congruity: Toward a Theory of Personality and Cybernetics: Praeger.

Sirgy, J. et al, 2008. Effect of self-congruity with sponsorship on brand loyalty. Journal of Business Research, Vol.61, No.10, pp. 1091-1097.

Schivinski, B. et al, 2016. Measuring Consumers' Engagement With Brand-Related Social-Media Content. Development and Validation of a Scale that Identifies Levels of Social-Media Engagement with Brands, Vol. 56, No.1, pp. 64-80. 